\title{
Dip-coated hydrotungstite thin films as humidity sensors
}

\author{
G V KUNTE, UJWALA AIL, S A SHIVASHANKAR and A M UMARJI* \\ Materials Research Centre, Indian Institute of Science, Bangalore 560 012, India
}

MS received 6 December 2004; revised 28 February 2005

\begin{abstract}
Thin films of a hydrated phase of tungsten oxide, viz. hydrotungstite, have been prepared on glass substrates by dip-coating method using ammonium tungstate precursor solution. $X$-ray diffraction shows the films to have a strong $b$-axis orientation. The resistance of the films is observed to be sensitive to the humidity content of the ambient, indicating possible applications of these films for humidity sensing. A homemade apparatus designed to measure the d.c. electrical resistance in response to exposure to controlled pulses of a sensing gas has been employed to evaluate the sensitivity of the hydrotungstite films towards humidity.
\end{abstract}

Keywords. Tungsten oxide; hydrotungstite; humidity sensing.

\section{Introduction}

Tungsten oxides have been studied extensively because of applications in electrochromic devices. Tungsten oxide and binary systems of tungsten oxide with other transition metal oxides are also being studied for their gas sensing applications. Thin films of tungsten oxide have been prepared by various physical and chemical methods of thin film deposition, often leading to different properties (Granqvist 1995). Tungsten oxide films for $\mathrm{NO}_{x}$ sensing have been produced by thermal evaporation of tungsten oxide powder (Cantalini et al 1996). Tungsten oxide films have been grown by d.c. and r.f. sputtering and have been studied for their electrochromic and gas sensing properties (Smith et al 1993). Electrochemical and chemical techniques have been widely employed for the preparation of tungsten oxide films. Tungsten oxide films for electrochromic applications have been grown by chemical vapour deposition using hexacarbonyl tungsten as precursor (Maruyama and Arai 1994), and with tungsten ethoxide as precursor (Riaz 1993). Other techniques such as plasmaenhanced chemical vapour deposition have also been used. Sol-gel techniques have also been employed, using different precursors such as tungsten oxychloride (Pyper et al 1998) and tungstic acid (Bedja et al 1994).

A variety of hydrated phases of tungsten oxides, often called the tungstic acids, have been investigated for a long time. Most of these hydrated compounds are prepared through solution routes, and a large amount of literature is available on the preparation and characterization of these compounds (Gerand et al 1981). Recently, a detailed study of tungsten oxide powders prepared from different tungstic acids has been reported (Nogueira et al 2004).

\footnotetext{
*Author for correspondence (umarji@mrc.iisc.ernet.in)
}

The use of activated tungsten oxide as a gas sensor was first reported in 1967 (Shaver 1967). Since then, in recent years, there has been an interest in the study of tungsten oxides for sensing applications. Tungsten oxide-based materials have been used for the sensing of various gases, especially for $\mathrm{H}_{2} \mathrm{~S}$ (Barrett et al 1990), $\mathrm{NO}_{x}$ (Nelli et al 1996) and ozone (Qu and Wlodarski 2000). A variety of tungstate materials such as manganese tungstate in the form of thick films, have been studied for humidity sensors (Qu and Mayer 1997). The humidity sensing characteristics of bulk metal oxide-tungsten oxide systems have also been studied in literature (Ichinose 1993).

In this work, thin films of hydrated tungsten oxides have been prepared on glass substrates by dip-coating method. Phase identification by X-ray diffraction and scanning electron microscopy are reported. The $b$-axis oriented hydrotungstite films have been tested for their humidity sensing properties.

\section{Experimental}

Thin films of a hydrated form of tungsten oxide $\left(\mathrm{H}_{2} \mathrm{WO}_{4}\right.$. $\mathrm{H}_{2} \mathrm{O}$ ) were grown on amorphous glass substrates by a simple dip-coating technique. The precursor used for dipcoating was ammonium tungstate $\left(\left(\mathrm{NH}_{4}\right)_{2} \mathrm{WO}_{4} \cdot x \mathrm{H}_{2} \mathrm{O}\right)$, that was prepared by dissolving tungstic acid $\left(\mathrm{H}_{2} \mathrm{WO}_{4}\right.$, Fluka) in liquor ammonia. The films were grown on glass substrates by dipping the substrates into the precursor solution (0.05 M ammonium tungstate solution in water) and drying the substrate at $100^{\circ} \mathrm{C}$ over a hot plate. This dipping and drying process was repeated in order to increase thickness of the films. After this, the films were calcined in a furnace in air at $500^{\circ} \mathrm{C}$ for $4 \mathrm{~h}$. The films were allowed to cool in air inside the furnace, and removed after room temperature was reached. The calcination temperature was chosen based on the thermogravimetric 
analysis of ammonium tungstate (carried out on a TA Instruments SDTQ 600), as discussed below.

The crystallographic phase of the film was identified by X-ray diffraction (XRD, Philips model PW 1050/37, $\mathrm{CuK}_{\alpha}$ radiation). A scanning electron microscope (SEM, Cambridge Stereoscan S-360) was employed to study the surface morphology of the films and to deduce film thickness by cross-sectional SEM.

The electrical resistance and humidity sensing properties were measured in an experimental set up designed and fabricated in house. Relative humidity in the range of 5-100\% was obtainable in this set up. A schematic of the set up is shown in figure 1. It consists of a stainless steel sample holder capable of holding a sample of size $6 \times$ $6 \mathrm{~mm}$. The holder also carries four electrical platinum probes used for electrical resistance measurement. A type-K thermocouple placed in proximity to the holder is used to record the temperature of the sensor. The sample holder is equipped with a small heater of nichrome wire capable of heating the sensor to $450^{\circ} \mathrm{C}$. The sample holder is enclosed in a quartz cup whose one end is connected to the atmosphere control system. This arrangement allows the ambient around the sensor to be changed quickly. The entire arrangement is enclosed inside a quartz tube, surrounding which is a furnace capable of heating the system to $800^{\circ} \mathrm{C}$, with controlled heating and cooling rates.

The ambient control system consists of two lines-the line for the carrier gas (zero gas), and the test gas line, which carries the gas or vapours of a liquid to be sensed. (In the latter case, this is done by bubbling the carrier gas through the liquid). The test gas is mixed with the carrier gas (air) for varying the test gas concentration. Gas flow through both lines is controlled by electronic mass flow controllers (MFC) and timer-controlled solenoid valves. The MFCs operate in the range of $0-100 \mathrm{sccm}$. The sequence of opening the valves and the time of their opening allow variation of sensing gas concentration over a wide range.

Both two-probe and four-probe measurements of sample resistance are possible in the system. The resistance of the sensor is measured by a multimeter (Keithley 2700), which also measures the temperature signal, both being recorded on the computer through the IEEE-488 interface. This allows the sensor resistance to be studied

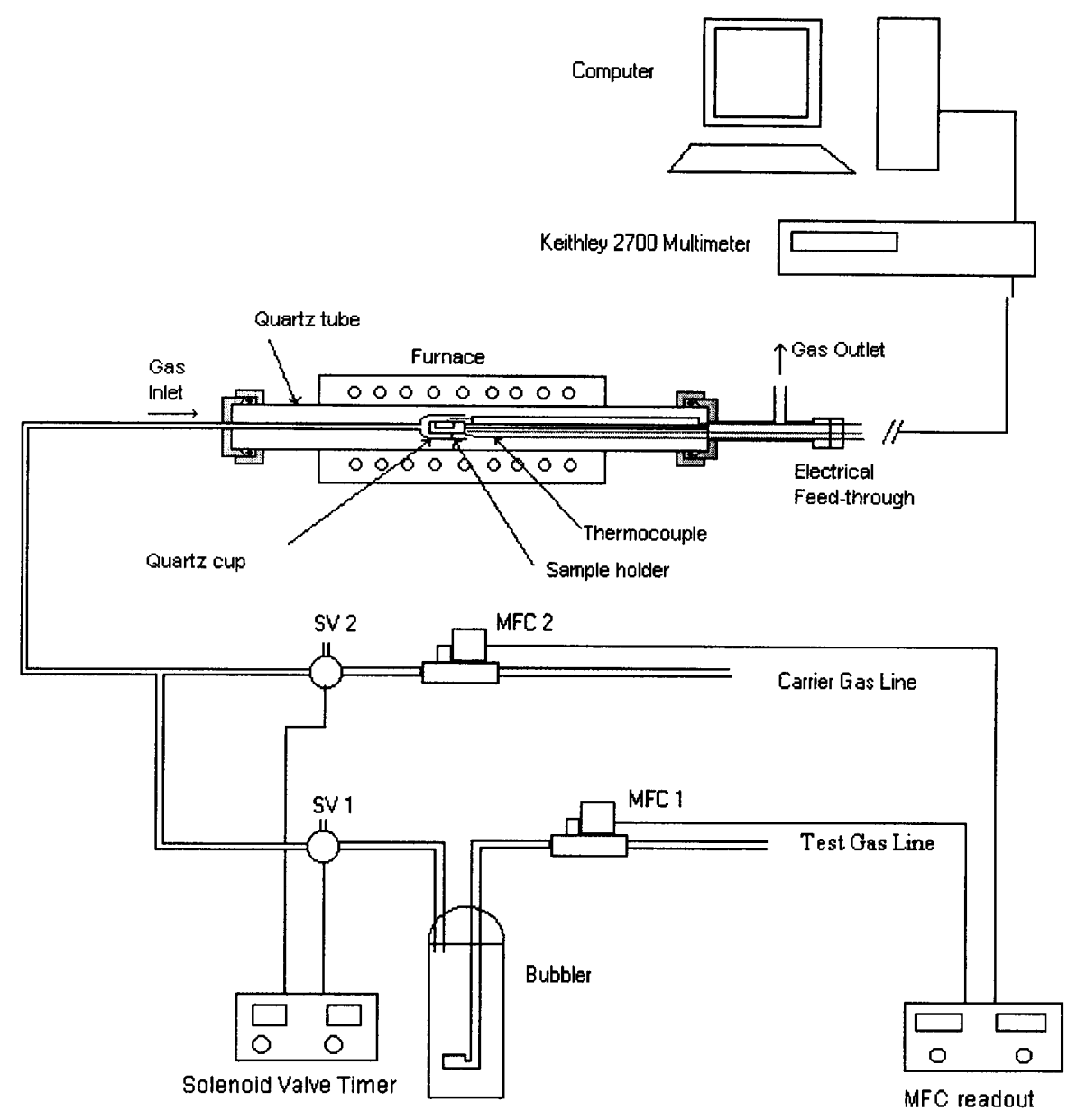

Figure 1. Schematic of the gas-sensing apparatus. 
as a function of temperature, as well as to record resistance and temperature as a function of time throughout the experiment. In this work, the resistance of the films has been monitored during controlled exposure to relative humidity in the range $5-85 \%$.

\section{Results and discussion}

\subsection{Film preparation and $X$-ray diffraction analysis}

The results of the thermogravimetric analysis/differential thermal analysis (TGA/DTA) of ammonium tungstate solid are shown in figure 2. The plot shows that ammonium tungstate decomposes through loss of water and ammonia, and the decomposition to form tungsten oxide, $\mathrm{WO}_{3}$, is complete by $500^{\circ} \mathrm{C}$. Based on this information, the calcination temperature for the films was chosen as $500^{\circ} \mathrm{C}$. The films were thus calcined at $500^{\circ} \mathrm{C}$ for $4 \mathrm{~h}$, and then furnace-cooled to room temperature.

The phase formed upon calcination was expected to be $\mathrm{WO}_{3}$. However, X-ray diffraction studies indicated the films to consist of a hydrated phase of tungsten oxide, hydrotungstite $\left(\mathrm{H}_{2} \mathrm{WO}_{4} \cdot \mathrm{H}_{2} \mathrm{O}\right)$. The X-ray diffraction pattern of a typical film and the corresponding JCPDS pattern (JCPDS File No. 18-1420) are shown in figure 3. This observation was limited to the first calcination step only. Any subsequent heating of the films, even to $150^{\circ} \mathrm{C}$, resulted in the irreversible loss of the hydrated phase. Heating the films to $500^{\circ} \mathrm{C}$ resulted in the formation of anhydrous $\gamma-\mathrm{WO}_{3}$, which was identified by X-ray diffraction.

The reasons for the formation of this phase (hydrotungstite) instead of the expected phase is not clear, though it may be said that this particular method of film preparation and processing seems to favour the formation of the hydrated phase, which otherwise decomposes above $150^{\circ} \mathrm{C}$.

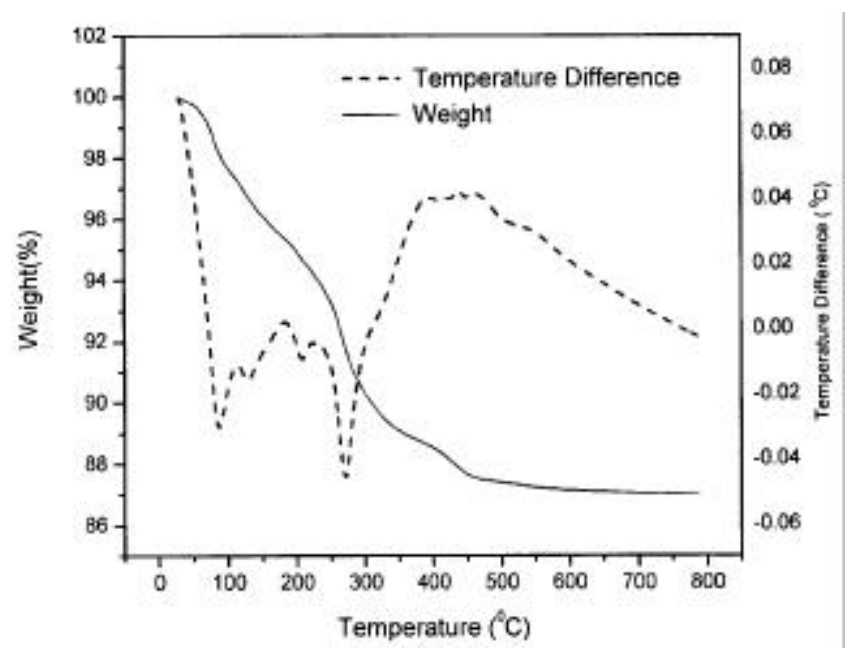

Figure 2. Thermal analysis (TGA/DTA) of ammonium tungstate.
The film is seen to have a strong $b$-axis orientation, with only the peaks corresponding to the (010), (020) and (030) planes being seen in the X-ray pattern.

When a film is grown on an amorphous substrate, the substrate, having no ordered structure of its own, would ordinarily not be expected to influence orientation of the film. However, it is sometimes seen that highly oriented films are obtained on amorphous substrates such as glass. This can be explained on the basis that, in order to minimize the film-substrate surface interfacial energy, and hence achieve a stable configuration, the film grows preferentially in a direction normal to the crystallographic plane which is the most densely packed in the structure (Yoon and Flanders 1978; Yoon et al 1999). A few of the crystallographic planes in the hydrotungstite structure and the atomic density in those planes are shown in figure 4. (These planes have been drawn using the Diamond 2.0 software). The (010) plane is seen to be the most densely packed in the structure. This plane is thus formed first on the amorphous substrate surface, in order to minimize surface energy. Hence, the film grows in an oriented manner, normal to the most densely packed plane. This explains the formation of $b$-axis oriented hydrotungstite films on glass substrates.

\subsection{Scanning electron microscopy}

The surfaces of the films were observed by SEM to be rough, with the presence of particulates on the surface (figure 5a). The average size of these particulates was estimated to be $0 \cdot 1 \mu \mathrm{m}$. The film is topped by a lot of particulates, but the underlying film is not really rough. The bright contrast of the particulates suggests that they comprise a material different from that of the underlying hydrotungstite. However, the proportion of the particu-

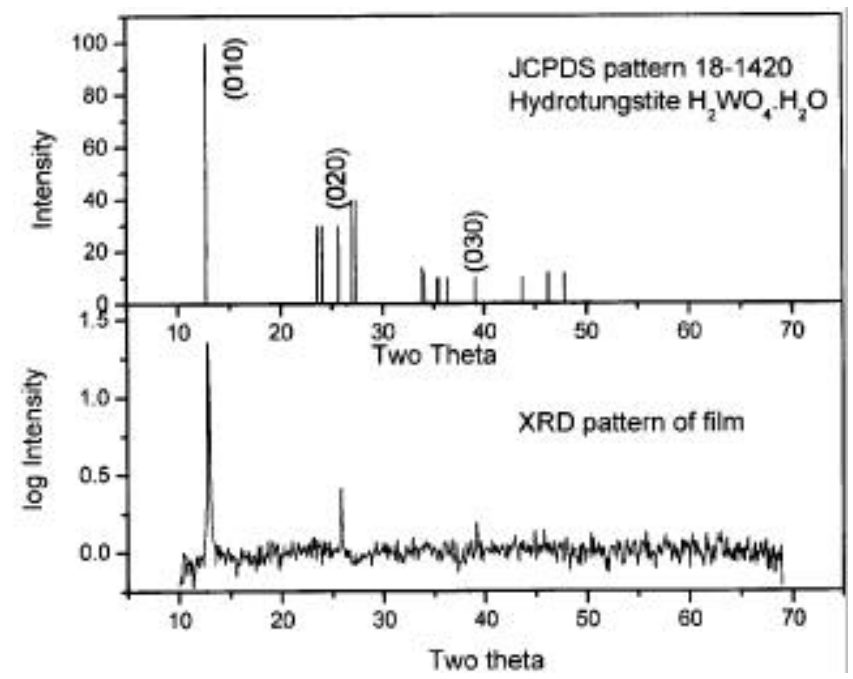

Figure 3. XRD pattern of the film and the corresponding JCPDS pattern. 
late material (which appears to lie only at the surface) is not enough to be characterized by XRD. As such, the particulates may be formed by that part of the dip-coated film, which is loosely bonded to the underlying film. Because of this loose binding the particulates reach a higher temperature during the calcinations of the dip-coated layer, resulting in a surface layer of different composition and, ostensibly, a different crystallographic structure. From cross-sectional SEM analysis, film thickness is estimated to be $\sim 5 \mu \mathrm{m}$. A cross-sectional view of the film is shown in figure $5 b$.

\subsection{Electrical resistance measurements}

The resistance of the film as a function of temperature was measured in air, by the two-probe method, using interdigitated gold electrodes sputtered onto the film for the purpose. The nature of the contact was verified to be ohmic by $I-V$ measurements.

The films were seen to be quite resistive, with a resistance of the order of giga-ohms in dry air. It is observed that the resistance initially increases up to $150^{\circ} \mathrm{C}$. This is followed by a decrease in the resistance when the temperature is raised further, as may be expected for the semiconducting phase, $\gamma-\mathrm{WO}_{3}$. The initial increase in resistance on heating may be due to the loss of water from the film. X-ray diffraction of the film after $R-T$ measurement indicates the irreversible formation of the anhydrous $\mathrm{WO}_{3}$ phase. These results showed that the electrical properties of the films are sensitive to temperature and to the moisture content (humidity) in the ambient. It was hence decided to investigate the humidity-sensing properties of these films for possible application as humidity sensors.

\subsection{Humidity-sensing measurements}

The electrical resistance of the films was measured as a function of humidity in the ambient. Different values of relative humidity were obtained by mixing dry nitrogen gas that was completely saturated with water vapour by bubbling it through water, with dry air. In the course of the experiment, the resistance of the film was measured continuously with switching of atmosphere from dry air

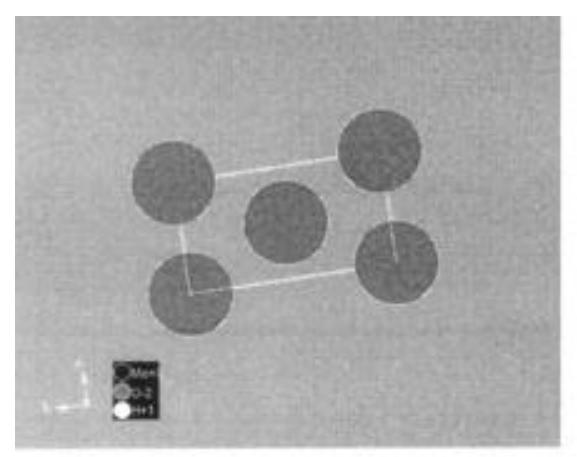

(100)
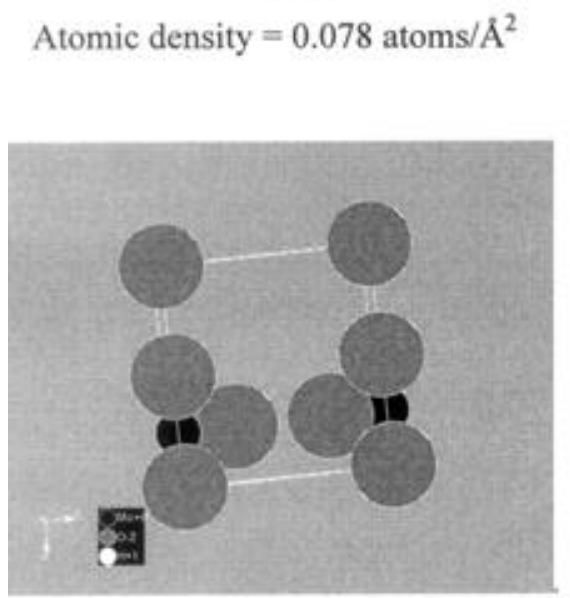

(001)

Atomic density $=0.096$ atoms $/ \AA^{2}$

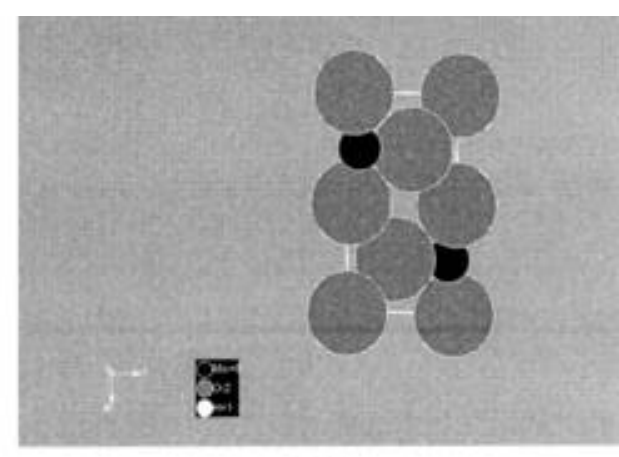

(010)

Atomic density $=0.180$ atoms $/ \AA^{2}$

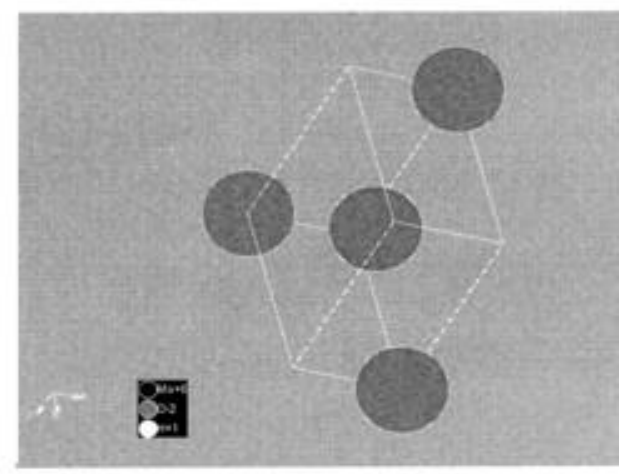

(111)

Atomic density $=0.062$ atoms $/ \AA^{2}$

Figure 4. Atomic arrangements in various crystallographic planes in $\mathrm{H}_{2} \mathrm{WO}_{4} \cdot \mathrm{H}_{2} \mathrm{O}$. 

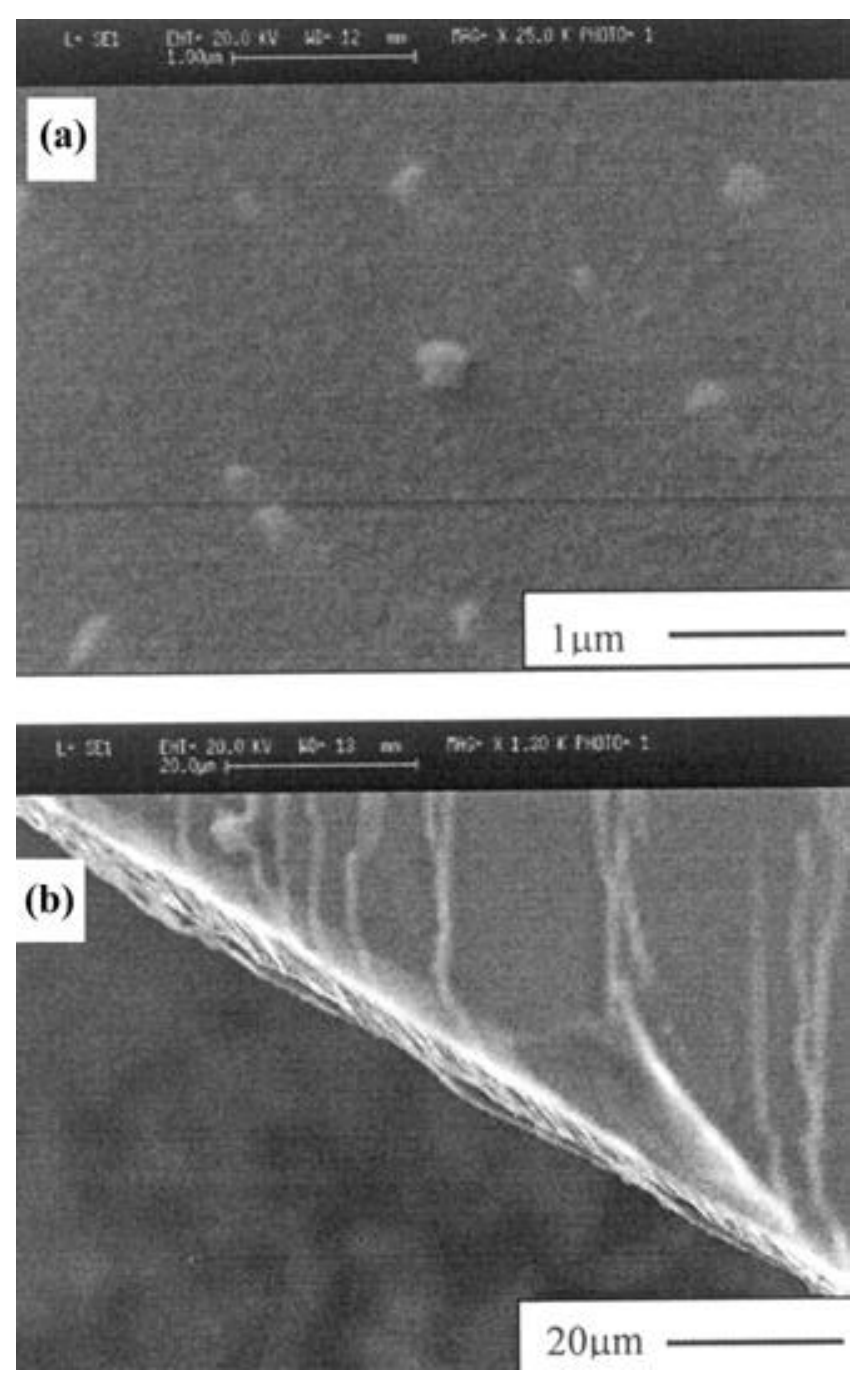

Figure 5. SEM image of hydrotungstite film: (a) surface showing particulates on a smooth underlayer and (b) cross-sectional views of the film.

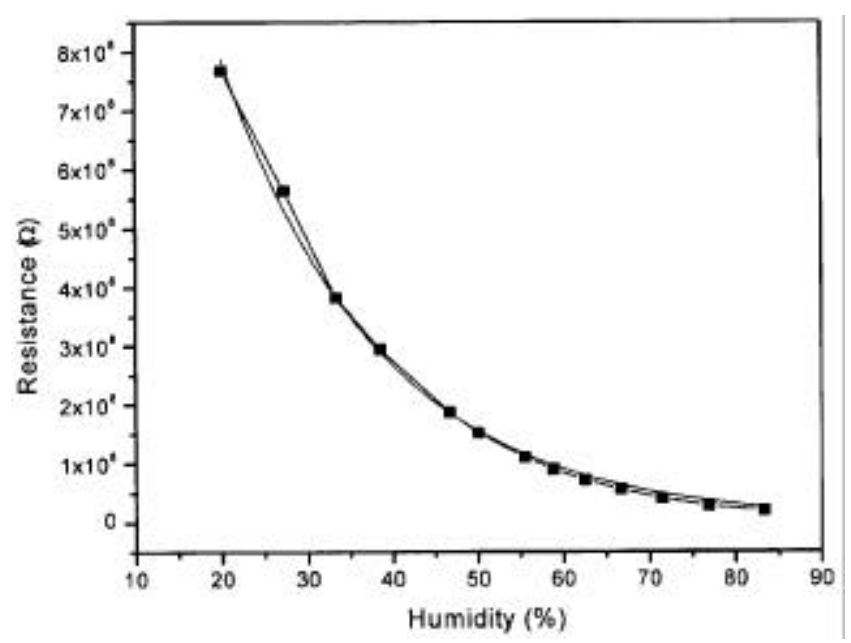

Figure 6. Film resistance vs \% relative humidity for hydrotungstite film at room temperature. to an atmosphere with a known value of relative humidity, as a function of time.

The plot of film resistance vs relative humidity, measured at room temperature, is shown in figure 6 . The film resistance was seen to decrease exponentially with the increase of relative humidity in the ambient. The unbroken curve shows the exponential fit to the experimental data, illustrating clearly the good quality of the fit.

The response time of the film is of the order of $45 \mathrm{~s}$, with a recovery time of the order of $100 \mathrm{~s}$. It is also observed that with an increase in temperature, the sensitivity of the films to humidity reduces, and no sensitivity is seen above $50^{\circ} \mathrm{C}$. The films are also observed to be insensitive to other chemicals such as ethanol, acetone, hexane and toluene, indicating that the sensing behaviour is selective to humidity. It is also observed that the sensitivity to humidity (measured at room temperature) is completely lost if the films are first exposed to temperatures higher than $150^{\circ} \mathrm{C}$. Irreversible changes are observed in the X-ray diffractograms, which is being investigated further to understand the mechanism of sensing. This indicates that the mechanism of sensing is related to the interaction of protons in the gas phase with a specific surface of the crystallographically oriented film.

\section{Conclusions}

Thin films of the tungsten oxide-based material, hydrotungstite, were prepared on glass substrates by the dipcoating technique, using a solution of ammonium tungstate as a precursor solution. The films so obtained were characterized by X-ray diffraction and scanning electron microscopy. The resistance of these films was high, and found to be dependent on the humidity of the ambient, suggesting their suitability as humidity sensors. The films are selective in their response to humidity, being insensitive to the vapours of chemicals such as ethanol, acetone, hexane, and toluene.

\section{References}

Barrett E P S, Georgiades G E and Sermon P A 1990 Sensors Actuators B1 116

Bedja I, Hotchandani S, Carpenties R, Vinodgopal K and Kamat P V 1994 Thin Solid Films 347195

Cantalini C, Pelino M, Sun H T, Faccio M, Santucci S, Lozzi L and Passacantando M 1996 Sensors Actuators B35-36 112

Gerand B, Nowogrocki G and Figlarz M 1981 J. Solid State Chem. 38312

Granqvist C G 1995 Handbook of inorganic electrochromic materials (Amsterdam: Elsevier B)

Ichinose N 1993 Sensors Actuators B13-14 100

Maruyama T and Arai S 1994 J. Electrochem. Soc. 1411024

Nelli P, Depero L E, Ferroni M, Groppelli S, Guidi V, Ronconi F, Sangaletti L and Sberveglieri G 1996 Sensors Actuators B31 89 
Nogueira H I S, Cavaleiro A M V, Rocha J, Trindade T and Pedrosa de Jesus J D 2004 Mater. Res. Bull. 39683

Pyper O, Schollborn R R, Donkers J J T M and Krings L H M 1998 Mater. Res. Bull. 331095

Qu W and Mayer J-U 1997 Sensors Actuators B40 175

Qu W and Wlodarski W 2000 Sensors Actuators B64 42
Riaz U 1993 Thin Solid Films 23515

Shaver P J 1967 Appl. Phys. Lett. 11255

Smith D J, Vetelino J F, Falconer R S and Wittman E L 1993 Sensors Actuators B13 264

Yoon J-G and Flanders D C 1978 Appl. Phys. Lett. 32349

Yoon J-G, Oh H K and Lee S J 1999 Phys. Rev. B60 2839 